\title{
OS CICLOS NO BRASIL: LIMITES E POSSIBILIDADES
}

\author{
JÉSSICA MARTINS MANTOVAN ${ }^{1}$
}

\begin{abstract}
RESUMO
As políticas de ciclos no Brasil têm gerado polêmica e discussões desde a sua implantação, sendo que as críticas em relação a essa forma de organização têm se intensificado ao longo do tempo. A partir disso, cabe questionar: quais são as possibilidades e limites que têem se revelado no desenvolvimento do sistema em ciclos no Brasil? Objetivando investigar esses aspectos, este artigo, de caráter qualitativo, buscou a partir de uma pesquisa bibliográfica, refletir sobre as contribuições desse regime, assim como acerca das dificuldades e desafios que dele emergem. Como fundamentação teórica, utilizou-se os estudos de Barreto e Mitrulis (1999), Freitas (2003), Mainardes (2007; 2009), Bahia (2012), Palma Filho; Alves e Duran (2012), Souza (1998; 2004; 2017), entre outros. Constatou-se que apesar das dificuldades, os ciclos demonstram estar tocando em contradições importantes, pois contrariam a lógica excludente e seletiva da escola, porém, um grande desafio que ainda permanece é que, além de regular o fluxo escolar, as mudanças advindas dessa política resultem em uma efetiva qualidade de ensino na educação pública.
\end{abstract}

Palavras-chave: Sistema de ciclos. Progressão continuada. Reorganização curricular.

Este trabalho é fragmento do primeiro capítulo da pesquisa de mestrado realizada no Programa de Pós-Graduação em Educação da Universidade Metodista de São Paulo, intitulada "A PROPOSTA DE REORGANIZAÇÃO DE CICLOS IMPLANTADA EM 2014 NO MUNICÍPIO DE SÃO PAULO: IMPACTOS INICIAIS E A REAÇÃO DOS PROFESSORES”, defendida no ano de 2017, com a orientação do Prof. Dr. Roger Marchesini de Quadros Souza. 


\begin{abstract}
Cycle politics in Brazil have generated controversy and discussions since its implementation, and criticisms of this form of organization have intensified over time. From this, it is a good question: what are the possibilities and limits that have been revealed in the development of the system of cycles in Brazil? Aiming to investigate these aspects, this article, of a qualitative nature, sought from a bibliographical research, to reflect on the contributions of this regime, as well as on the difficulties and challenges that emerge from it. As a theoretical basis, was used the studies of Barreto and Mitrulis (1999), Freitas (2003), Mainardes (2007; 2009), Bahia (2012), Palma Filho; Alves and Duran (2012), Souza (1998, 2004, 2017), among others. It was observed that despite the difficulties, the cycles demonstrate important contradictions, because they contradict the exclusionary and selective logic of the school, but a great challenge that still remains is that in addition to regulating the school flow, the changes resulting from this policy result in an effective quality of education in public education.
\end{abstract}

Key-words: Cycle system. Continued progression. Curricular reorganization.

\title{
INTRODUÇÃO
}

Nenhuma política pública é a-histórica, uma vez que resulta de todo um contexto anterior que não pode ser desconsiderado.

As questões voltadas à democratização da escola no Brasil vêm desde as décadas de 1920 e 1930, a partir da justificativa do alto índice de analfabetismo constatado nesse período (SOUZA, 2004). Dirigentes de ensino e educadores já " [...] reconheciam o fraco desempenho da escola brasileira e a gravidade da situação" (BARRETO; MITRULIS, 1999, p. 29).

Barreto e Mitrulis (1999) salientam que, entre 1940 a 1980, o índice de repetência no Brasil oscilava entre 60\% a 50\% nas passagens da $1^{a}$ para a $2^{a}$ série do ensino fundamental, o que dificultava a acessibilidade à escola, e denunciava a emergência de uma reformulação educacional. Nessa perspectiva, já se tinha claro a seletividade do sistema, problema que dificultava 
o desenvolvimento do país. Assim, iniciou-se a discussão em prol da promoção automática, inclusive o presidente Juscelino Kubitscheck, em 1956, pronunciava-se a favor dessa medida.

Dados de 1954, relativos à população de crianças na faixa de 7 a 10 anos e à matrícula escolar nas quatro séries da escola primária, autorizavam a afirmar que, na ausência de reprovações, ou seja, se se adotasse a matrícula por idade cronológica, o sistema paulista já apresentava um quadro de vagas escolares que excedia as necessidades do estado (BARRETO; MITRULIS, 1999, p. 29).

O pressuposto para a implantação da promoção automática na década de 1950, segundo Mainardes (2007), justificava-se no sentido de:

- Reduzir as taxas de reprovação e o desperdício de recursos financeiros.

- Aumentar o número de vagas na escola.

- Estabelecer um padrão de organização escolar mais moderno, utilizado em países mais desenvolvidos (p. 55).

Além disso, discutia-se que a retenção trazia outros inconvenientes, como diminuição da autoestima do aluno, desgosto da família, desestímulo à aprendizagem, sendo inútil, e produzindo consequências catastróficas.

A década de 1980 foi marcada por importantes medidas de reestruturações escolares, como a implantação do Ciclo Básico - CB - no Estado de São Paulo, Minas Gerais e Paraná. Palma Filho; Alves e Duran (2012) explicam que "O ponto principal da reorganização incidiu sobre as séries iniciais, agrupando-as em um único ciclo de estudos" (p. 173). Vale ressaltar que essa foi a primeira vez que o termo "ciclo" foi utilizado, embora a proposta do CB se assemelhasse ao "Bloco único" implantado no Rio de Janeiro de 1979 a 1984, expandindo-se posteriormente para outros Estados.

Apesar do intenso esforço de se superar o caráter fragmentário das séries, a reestruturação de todo o Ensino Fundamental 
só aconteceu no município de São Paulo em 1992, na gestão de Luiza Erundina. Havendo posteriormente se expandido para o Estado de São Paulo em 1998, com o regime de progressão continuada, modelo que permanece até os dias atuais e vem sendo bastante criticado pela comunidade escolar.

A partir do exposto, com as pesquisas já realizadas sobre as políticas de ciclos, desde a sua implantação, mais efetivamente a partir dos anos 1990, este estudo objetiva refletir acerca das dificuldades, contradições e problemas que emergem nesse regime, assim como identificar suas contribuições e possibilidades.

\section{CONTRIBUIÇÕES DOS CICLOS}

Mainardes (2009) aponta inúmeras vantagens decorrentes da organização em ciclos na educação, com destaque para a ruptura total ou parcial da reprovação. Essa medida oportuniza mais tempo de aprendizagem aos alunos, que podem, dessa forma, permanecer na escola, independentemente de seu nível econômico e receber um apoio mais apropriado para que avancem no processo de aprendizagem com outras crianças da mesma faixa etária, que têm os mesmos interesses e características. Assim, esse sistema é mais adequado para a classe trabalhadora, uma vez que cria condições para a continuidade da aprendizagem por intermédio de uma reestruturação do currículo e de uma avaliação diagnóstica e formativa, ao invés da classificatória, presente na escola seriada. $O$ autor pontua também que a escola ciclada cria novas necessidades de investimento em educação, como formação para os professores, oferta de estudos complementares, aquisição de materiais pedagógicos, entre outras, e afirma que "tais investimentos podem conduzir a avanços nas condições materiais das escolas e na condição do trabalho dos professores" (p. 68). Entretanto, quando essas ações não ocorrem, abre-se espaço para a resistência e a dificuldade de aceitação dos ciclos, em detrimento do sucesso desse sistema.

Redua (2003) concorda com essas contribuições, ressaltando que, quando se fala em ciclos, dois aspectos ganham mais ênfase: um é a desseriação, que consiste na "[...] possibilidade de organização da aprendizagem em tempos mais longos do que um 
ano letivo" (p. 18), o outro é a questão do fim ou diminuição da reprovação/aprovação, que sugere uma "[...] avaliação final que pune o aluno pelo não aprendizado e o obriga a repetir a série, independentemente do que aprendeu no ano letivo" (p. 18), o que pode desestimular o aluno a frequentar a escola por deixar de acreditar em suas capacidades intelectuais. Sobre o primeiro aspecto, Souza (2004) acrescenta:

Essas reformas educacionais procuram desenvolver um novo modelo temporal que hipoteticamente responderia de forma mais eficiente ao tempo necessário para o desenvolvimento do processo de aprendizagem do aluno [...] (p. 59).

Em relação ao segundo aspecto, vários estudos apontam que a reprovação não é a solução para os problemas de aprendizagem existentes na escola, ao contrário, ela evidencia uma ruptura no processo de desenvolvimento do aluno. A escola seriada, pautada pelo pressuposto de que todos devem aprender os conteúdos determinados no mesmo período - que seria de um ano, senão devem repetir a série e rever o que já foi estudado novamente -, desconsidera a construção do aluno e sua individualidade. Sendo assim, o princípio predominante nesse tipo de organização é o da seletividade, não da democracia. Nas diretrizes curriculares, o MEC enfatiza que “[...] o combate à repetência não pode significar descompromisso com o ensino e a aprendizagem" (BRASIL, 2013, p. 121).

Bahia (2012) salienta que isso é realmente um perigo, porque no intuito deminimizar-se o estigma do fracasso para não afetar a autoestima, reconhecem-se os avanços dos alunos, porém isso não é o suficiente para corrigir a defasagem que muitos apresentam.

Nesse sentido, é possível afirmar que algumas das vantagens vindas dos ciclos, se não forem bem pensadas, implantadas e executadas, podem transformar-se em dificuldades, por isso os ciclos podem ser potencialmente problemáticos. 


\section{DIFICULDADES REFERENTES AOS CICLOS}

Segundo Souza (2004), o nó górdio desse modelo, especialmente no Ensino Fundamental no Estado de São Paulo, objeto de sua pesquisa, é que "[...] a ideia da terminalidade pela seletividade de cada série deve ser substituída pela ideia de continuidade durante o período da duração de cada ciclo" (p. 58). Nota-se que em muitos casos essa continuidade não acontece na prática, como é apontado por Mainardes (2009):

Embora uma das justificativas para a implantação dos ciclos seja a possibilidade de se manter a continuidade do processo de aprendizagem, sem interrupções (causadas pela reprovação), isso nem sempre é garantido. As pesquisas indicam que, em muitos casos, os diferentes níveis e necessidades de aprendizagem não são devidamente atendidos nas escolas. As turmas são bastante heterogêneas e as situações de ensino, geralmente, são uniformes e baseadas no nível de domínio dos alunos de desempenho médio (p. 70 , parênteses do autor).

Observa-se que, na proposta de ciclos, a heterogeneidade não é vista de forma negativa, pois faz parte da dinâmica da vida humana (MAINARDES, 2009). Os diferentes níveis de aprendizagem podem contribuir para a troca de saberes entre os alunos e permitem uma construção mútua, porém é necessário que o professor tenha um olhar diferenciado formando as parcerias a partir dos diferentes níveis e propondo desafios diversos para que todos avancem. Isso pode configurar-se em uma dificuldade, seja pelo currículo rígido que prevê o ensino de determinados conteúdos a cada ano letivo, seja pela própria resistência dos professores, cujas "[...] identidades e crenças normalmente estão relacionadas ao sistema seriado" (MAINARDES, 2007, p. 16). Assim, é possível perceber que a seriação está presente no interior dos ciclos e, para uma grande parte dos docentes, o que mudou realmente foi a impossibilidade da reprovação simplesmente por uma correção de fluxo, causando críticas e conflitos 
que se afastam da ideia central de formação humana dos ciclos e geram a nomenclatura "promoção automática".

Em relação à reação dos professores, Souza (1998) destaca que ela pode apresentar-se de três formas " [...] a primeira, de aceitação das mudanças propostas; a segunda, de não aceitação explícita e a terceira, de não aceitação silenciosa" (p. 121), sendo que as duas últimas podem desdobrar-se em um hiperconformis$\mathrm{mo}^{2}$, gerando uma resistência declarada ou camuflada.

Uma das razões da resistência dos professores apontada por Arroyo (1999) é que, muitas vezes, as políticas públicas desconsideram a história e saberes dos professores, julgando que estes podem mudar sua prática a cada reforma. Segundo Bahia (2012), quando estes não são consultados em relação ao trabalho que vinham desenvolvendo, e suas necessidades ou expectativas não são consideradas, não se sentem respeitados enquanto profissionais. Mainardes (2009) concorda com essa posição quando afirma:

Os professores têm suas histórias, suas concepções, crenças, modos de ensinar e não se apropriam do discurso dominante (e que oscila de tempos em tempos, de acordo com as arquiteturas político-partidárias e ideológicas) por uma adesão pura e simples (p. 79, parênteses do autor).

Há de se considerar que uma mudança drástica gera um tempo de assimilação, aceitação e rompimento de paradigmas, por isso não pode ser implantada em "um só golpe" e sem a participação da comunidade, como ocorreu no Estado de São Paulo, em 1998, conforme pesquisa de Souza (2004). Para esse autor, quando novas reformas são implantadas há um choque entre as práticas já consolidadas e a necessidade de adequar-se aos novos modelos de avaliação e relações de ensino-aprendizagem característicos dos ciclos. A esse respeito, Bahia (2012) acrescenta: "Parece ingênuo supor que seja tranquilo alterar

2 Souza (2004) se refere a uma expressão usada por Patto (1996), que significa uma total apatia frente às mudanças. 
práticas, concepções e valores educacionais por meio de projetos governamentais" (p. 64).

Além disso, ressalta-se que quando as políticas públicas na Educação são impostas de cima para baixo, sem considerar a opinião dos maiores envolvidos e interessados na melhoria do ensino - os professores e pais - a probabilidade de o modelo fracassar aumenta. Como mencionado, Freitas (2003) esclarece que quando perdermos os professores haverá um impacto direto no processo de ensino-aprendizagem, e quando perdermos os pais, não vai haver uma apreciação em relação aos ciclos, e eles vão continuar vendo a escola como local para aprender somente Português e Matemática.

Destaca-se, assim, a importância de uma formação continuada consistente e aprofundada para os professores, uma vez que a falta desta pode levar a uma visão limitada da amplitude do contexto escolar e de seus problemas estruturais, e gerar a concepção de que o fracasso do aluno está diretamente relacionado aos ciclos, ocasionando um descrédito nestes.

É preciso pontuar que os fracassos da escola geralmente recaem sobre os professores. Medidas governamentais são implantadas e revestidas de um discurso de democratização e de qualidade de ensino quando, na verdade, estão responsabilizando os docentes pelo sucesso/insucesso dos alunos e dessas medidas, sem que lhes sejam oferecidas condições dignas de trabalho e de formação (BAHIA, 2012). Sobre isso, Freitas (2003) pondera que é importante reconhecer que os maiores problemas da escola têm origem histórico-social, "[...] não podemos ingenuamente afirmar que a forma que a escola assumiu na sociedade capitalista esteja voltada para ensinar tudo a todos" (p. 18), desconsiderando que a hierarquia econômica afeta a constituição das hierarquias escolares.

O papel da escola é o de "ensinar com qualidade todos os alunos" - sabedora de que não está isolada e de que os acontecimentos e a forma como a sociedade está organizada ao redor dela afetam o cumprimento deste papel (FREITAS, 2003, p.17, grifos da autora). 
Sendo assim, há de se levar em conta a lógica da submissão na qual a escola está inserida, "treinando" os alunos para ocupar uma posição no mercado de trabalho de acordo com sua classe social, de modo a instruí-los a se submeter aos tempos e às autoridades da escola sem questionamentos. Em alguns momentos, eles podem até ser convidados a participar de forma representativa, mas sem que lhes seja dada voz e autonomia para tomar as decisões e organizar sua própria vida escolar de fato. Freitas (2003) reforça essa questão quando explica:

A sofisticação das formas de controle da escola, em nossa sociedade, percebe que, ainda que o aluno permaneça na escola sem aprender Português e Matemática, há o ganho com o cumprimento da outra lógica - a da incorporação de práticas de submissão (p. 38).

Desse modo, o papel do professor é fundamental, porém por diversas razões, algumas já apontadas, nota-se uma desesperança em muitos professores, o que pode configurar-se em outra dificuldade para que o ideário dos ciclos se concretize.

Aflige-nos observarmos um certo imobilismo, ou conformismo, na postura de alguns profissionais, que parecem cansados, desencantados, pessimistas e que não crêem mais nas possibilidades concretas de uma atuação mais política e socialmente comprometida (BAHIA, 2012, p. 69).

Um dos fatores que desestimulam os educadores e acabam gerando resistência às propostas é a questão da descontinuidade dos trabalhos de uma gestão para a outra, em que muito do que se construiu é desconsiderado. Isso "[...] promove um período de desorientação e desorganização nas escolas, [...] gerando normalmente uma suspensão do envolvimento dos professores em ações que estavam sendo implementadas" (IBID., p. 55), como aconteceu no município de São Paulo após a implantação dos ciclos. 
Nesse cenário, é possível reconhecer que inúmeros são os desafios para o sucesso das políticas de ciclos. Alguns deles são apontados, a seguir.

\section{DESAFIOS NA ORGANIZAÇÃO EM CICLOS}

Um dos grandes desafios na implantação dos ciclos é a reorganização efetiva do currículo, que busque, efetivamente, alterar os tempos e espaços na escola e considere que é preciso tomar cuidado para não "[...] cair no extremo da configuração de um currículo técnico, prescritivo e centralizado” (MAINARDES, 2009 , p. 75). Conforme esse autor, as mudanças curriculares envolvem uma série de medidas complexas, como a revisão acerca do papel da escola e do conhecimento; a definição do modelo a ser adotado em relação às áreas de conhecimento, aos projetos e às metodologias variadas, que atendam às necessidades individuais dos alunos; o estabelecimento dos conhecimentos a serem privilegiados em cada ciclo; e uma articulação entre o currículo, a metodologia e a avaliação.

As diretrizes curriculares exprimem que a prioridade das ações deve ser atender às necessidades dos alunos.

Ciclos, séries e outras formas de organização a que se refere à Lei $\mathrm{n}^{\circ}$ 9.394/96 serão compreendidos como tempos e espaços interdependentes e articulados entre si, ao longo dos 9 (nove) anos. Ao empenhar-se em garantir aos alunos uma educação de qualidade, todas as atividades da escola e a sua gestão deverão estar articuladas com esse propósito. O processo de enturmação dos alunos, a distribuição de turmas por professor, as decisões sobre o currículo, a escolha dos livros didáticos, a ocupação do espaço, a definição dos horários e outras tarefas administrativas e/ou pedagógicas precisam priorizar o atendimento aos interesses e necessidades dos alunos (BRASIL, 2013, p.117, grifos da autora).

Cabe destacar o desafio de articular a comunidade escolar entre si na construção coletiva da política de ciclos e dos aspectos avaliativos. Para tanto, Mainardes (2009) sugere o uso de 
espaços de participação e canais de discussão livres de coerção. É importante que a articulação aconteça na escola também entre as diferentes áreas do conhecimento, pois para que a continuidade da aprendizagem aconteça é necessária a interação entre os professores das distintas disciplinas ou etapas do ciclo, organizando um currículo integrado. As Diretrizes Curriculares Nacionais para o Ensino Fundamental de 9 (nove) anos (BRASIL, 2013) apontam essa necessidade de superar o caráter fragmentário das áreas, favorecendo a participação de alunos com diferentes habilidades, interesses e experiências de vida, tornando, assim, mais significativos os conhecimentos.

Sem essa articulação não é possível romper com a fragmentação presente na seriação, porém, para que aconteça, é preciso que os professores tenham tempo de planejamento e melhores condições de trabalho. Além disso, é necessário investir na infraestrutura, materiais e formação dos professores, como já mencionado.

A implementação de políticas de ciclos - quando feita de forma cuidadosa e responsável - demanda investimento na infraestrutura das escolas (mais espaços, mais professores, estratégias de suporte aos alunos, um número menor de alunos nas salas de aula), bem como melhorias relacionadas às condições de trabalho docente: formação permanente, tempo para estudo e planejamento etc. (MAINARDES, 2009, p. 88, grifos da autora).

Outro desafio que merece ser destacado é o intuito dos ciclos de aproximar a escola da vida real, a qual por muitas vezes fica presa a conteúdos que destoam da realidade dos alunos e por isso o interesse e a função social se perdem e a aprendizagem deixa de ter sentido. Freitas (2003) explica o porquê desse distanciamento:

É fundamental entendermos o processo histórico de distanciamento da escola em relação à vida, em relação à prática social. Esse afastamento foi ditado por uma 
necessidade ligada à formação social capitalista, a qual, para apoiar o desenvolvimento das forças produtivas, necessitou de uma escola que preparasse rapidamente, e em série, recursos humanos para alimentar a produção de forma hierarquizada e fragmentada - e isso só era possível ser feito de forma escolarizada (p. 26-27).

As Diretrizes Curriculares Nacionais para o Ensino Fundamental de nove anos (BRASIL, 2013) criticam os currículos que se distanciam da vida cotidiana “...pelo caráter abstrato do conhecimento trabalhado e pelas formas de avaliação que servem apenas para selecionar e classificar os alunos, estigmatizando os que não se enquadram nas suas expectativas" (p. 118). É como se a escola estivesse isolada da vida ao invés de fazer parte dela, gerando práticas artificiais que conduzem a avaliações igualmente artificiais. Esses processos passam a ser o principal modo de "motivar" os alunos, gerando uma sequência por meio da qual os alunos decoram as informações transmitidas para trocar por nota e depois logo esquecem o que foi "aprendido", para memorizar, assim, outros conteúdos, e estes não se transformam em conhecimento de fato. Essas são as características típicas do ensino tradicional seriado, que reproduz os valores de uso e troca do sistema capitalista.

Considerar a realidade dos alunos é valorizar a diversidade presente na escola e respeitar as diferenças culturais e tipos de conhecimento, esses elementos constituem-se como princípios do sistema ciclado. Bahia (2012), entretanto, chama a atenção para um cuidado que se deve ter quando essa questão é apontada:

[...] o discurso (legítimo) sobre o respeito à diversidade dos alunos merece uma reflexão ponderada para não confundirmos este respeito com um "sucateamento" ou "rebaixamento" da qualidade de ensino, porque se corre o risco de, por considerar e respeitar esta diversidade, não se efetivar o investimento num ensino que garanta a aquisição de conhecimentos básicos e necessários a todos, mediado por critérios de avaliação consistentes e coerentes (p. 29, grifos e parênteses da autora). 
As mudanças em relação aos processos avaliativos constituem-se em grandes desafios trazidos pelos ciclos, pois quando a avaliação deixa de ser classificatória com a ameaça da reprovação, para ser formativa com uma proposta de aprendizagem contínua, gera um sentimento de impotência no professor, como se este estivesse perdendo seu instrumento de controle, sem nada para colocar no lugar. Há de considerar que a "cultura da repetência" permeia a escola há muitos anos. Nas palavras de Bahia (2012) “[...] a concepção de avaliação estava fortemente ligada à punição, gerando sucessivas reprovações nos alunos que eram obrigados a cursar a mesma série [...] o que contribuía para a desistência destes alunos da escola" (p. 54).

Por esse motivo, Mainardes (2009) sugere que as formações de professores os instrumentalizem, refletindo sobre estratégias diferenciadas de avaliação, a fim de obter informações diagnósticas acerca do processo de aprendizagem dos alunos e para o trabalho com os diferentes níveis nos quais se encontrem, além de propor formas de registro construídas coletivamente que sejam mais apropriadas para a realidade e contexto onde os discentes estejam inseridos. Dessa forma, os processos avaliativos teriam maior coerência com a política de ciclos. Bahia (2012) ressalta: “[...] há que lutarmos por um processo avaliativo não punitivo, não excludente, e que marque profundamente o destino de milhares de alunos de nossas escolas, os excluídos” (p. 62).

\section{CONSIDERAÇÕES FINAIS}

Apesar das dificuldades, os ciclos demonstram estar tocando em contradições importantes, haja vista todos os conflitos que têm gerado, pois contrariam a lógica excludente e seletiva da escola e da avaliação, o que significa um grande motivo para a permanência dessa forma de organização.

Cabe destacar que, com a sua implantação, sanou-se grande parte do problema do fluxo escolar, diminuindo os índices relacionados à evasão e falta de acesso à escola, porém, o fracasso escolar no âmbito da qualidade de ensino, ainda permanece como um dos grandes desafios a serem superados nesse modelo. 
Esse cenário denota a urgência da discussão e de um maior aprofundamento com novas pesquisas, sobre como as políticas de ciclos e as mudanças advindas delas podem redundar em uma efetiva qualidade de ensino.

\section{REFERÊNCIAS}

ARROYO, Miguel G. Ciclos de desenvolvimento humano e formação de educadores. Educação e Sociedade. Campinas, v. 20, n. 68, p. 142 -162, dez. 1999. BAHIA, Norinês Panicacci. O fracasso escolar e a reclusão dos excluídos. São Paulo: Alexa Cultural, 2012.

BARRETTO, Elba Siqueira de Sá; MITRULIS, Eleny. Os ciclos escolares: elementos de uma trajetória. Cadernos de Pesquisa, n. 108, p. 27-48, nov. 1999. BRASIL. Ministério da Educação. Diretrizes Curriculares Nacionais para o Ensino Fundamental de 9 (nove) anos. In: Diretrizes Curriculares Nacionais da Educação Básica. Brasília: MEC, 2013. Disponível em: < http://portal.mec. gov.br/index.php?option $=$ com_docman\&view $=$ download\&alias $=15548-d-c-n-$ -educacao-basica-nova-pdf\&Itemid=30192>. Acesso em 15 jan. 2016.

FREITAS, Luiz Carlos de. Ciclos, seriação e avaliação: confronto de lógicas. São Paulo: Ed. Moderna, 2003.

MAINARDES, Jefferson. Reinterpretando os ciclos de aprendizagem. São Paulo: Cortez, 2007.

MAINARDES, Jefferson. A escola em ciclos: fundamentos e debates. São Paulo: Cortez, 2009.

PALMA FILHO, João Cardoso; ALVES, Maria Leila; DURAN, Marília Claret Geraes. A reorganização do ensino fundamental em ciclos: trajetória dos últimos trinta anos no estado de São Paulo. Educação \& Linguagem. São Paulo, v. 15, n. 26, p. 169-191, jul./- dez. 2012.

REDUA, Marcia M. A organização do ensino em ciclos e as práticas escolares: investigação em uma escola da Rede Municipal de São Paulo. Dissertação de Mestrado em Educação. Pontifícia Universidade Católica de São Paulo. São Paulo, 2003.

SOUZA, Roger M. Q. Repetência Multidisciplinar: um estudo sobre o fracasso escolar no Ensino Fundamental. São Paulo: Dissertação de Mestrado em História e Filosofia da Educação, Pontifícia Universidade Católica de São Paulo, 1998.

SOUZA, Roger M. Q. Regime de ciclos com progressão continuada nas escolas públicas paulistas: um cenário para o estudo dos impactos das mudanças educacionais no capital cultural e habitus dos professores. Tese de Doutorado. Programa de Pós-Graduação em Educação: História, Política e Sociedade, Pontifícia Universidade Católica de São Paulo, 2004. 


\section{SOBRE A AUTORA}

Mestre em Educação pela Universidade Metodista de São Paulo - UMESP. Especialista em Psicopedagogia. Graduada em Pedagogia. Atualmente, é docente no curso de Pedagogia presencial e A distância da UMESP, e professora de Educação Infantil e Ensino Fundamental I na rede municipal de ensino de São Paulo. E-mail: je_mantovan@hotmail.com. 